\title{
Expression of receptor interacting protein 1 and receptor interacting protein 3 oval cells in a rat model of hepatocarcinogenesis
}

\author{
MARTA WÓJCIK $^{1}$, RYSZARD BOBOWIEC $^{1}$, URSZULA LISIECKA ${ }^{2}$ and ANNA ŚMIECH ${ }^{3}$ \\ Departments of ${ }^{1}$ Pathophysiology, ${ }^{2}$ Epizootiology and Clinic of Infectious Diseases and ${ }^{3}$ Pathological Anatomy, \\ Faculty of Veterinary Medicine, University of Life Sciences, 20-033 Lublin, Poland
}

Received September 4, 2017; Accepted February 8, 2018

DOI: $10.3892 /$ etm.2018.5988

\begin{abstract}
When apoptosis is suppressed in a neoplastic state, necroptosis may enable an anticancer response. In the present study, the association between apoptosis and necroptosis was assessed in a partial hepatectomy (PH)/diethylnitrosamine (DEN) rat model of hepatocarcinogenesis. Isolated oval cells (OCs) were analysed at 24, 48 and $72 \mathrm{~h}$ and at the first and second week of incubation. Phenotypic studies, apoptosis and necroptosis detection and proliferative activity assays were also performed on the OCs. The OCs were isolated from non-neoplastic (PH) and neoplastic (PH/DEN) livers, which expressed receptor interacting protein (RIP) 1 and RIP3. Western blot analysis revealed that the RIP1 and RIP3 expression in the PH/DEN OCs started to increase at $72 \mathrm{~h}$ and continually increased to the end of cell culture. Compared with the $\mathrm{PH}$ OCs, the cells isolated from $\mathrm{PH} / \mathrm{DEN}$ rats exhibited significantly less potential for apoptosis $(\mathrm{P}<0.05)$. There were a minimal number of apoptotic PH/DEN OCs $(2.82 \pm 1.1 \%)$ at $72 \mathrm{~h}$. In addition, the PH/DEN OCs demonstrated progressive proliferative activity during incubation, which was significantly increased compared with the PH OCs at $\geq 72 \mathrm{~h}$. The present study revealed that PH/DEN OCs, which trigger hepatic cancer, have a high proliferative activity and suppress apoptosis. It was also observed that, based on the expression of RIP3 and RIP1, necroptosis may be maintained and may serve as an alternative pathway for programmed PH/DEN OC death.
\end{abstract}

\section{Introduction}

Hepatocellular carcinoma (HCC) is the sixth most common type of cancer with an increasing incidence worldwide (1). Despite

Correspondence to: Dr Marta Wójcik, Department of Pathophysiology, Faculty of Veterinary Medicine, University of Life Sciences, 12 Akademicka, 20-033 Lublin, Poland

E-mail: marta.wojcik@up.lublin.pl

Key words: oval cells, apoptosis, necroptosis, hepatocellular carcinoma recent advances in treatment and the understanding of its pathophysiology, HCC remains a disease with a poor prognosis (1-2). HCC typically develops following chronic inflammatory liver disease caused by viral infection, which induces cirrhosis and exposure to chemical carcinogens (1) Treatment of advanced HCC disease is largely ineffective, primarily due to therapy-resistance mechanisms (2). At present surgical resection and liver transplantation are the best treatment options (2). However, a high rate of recurrence and metastasis post curative resection is common and is one of the major causes of mortality in patients with HCC (1-2). Liver oval cells (OCs) possess high proliferative activity, which when disrupted may contribute to HCC (3). The number of OCs may be used to evaluate the degree of necroptosis during chemical carcinogenesis as they are rarely isolated form a healthy liver (3-5).

Following OC transformation into cancerous cells, changes in apoptosis and necroptosis serve a key role in hastening the neoplastic state (6-8). To the best of our knowledge, previous studies of experimental hepatocarcinogenesis have only investigated the effect of a failure in one of these programmed cell death pathways $(6,9)$. A number of previous studies have highlighted the molecular basis of apoptosis resistance in hepatocarcinogenesis, associated with changes to cell death receptors $(6,9,10)$. A novel concept of programmed cell death known as necroptosis has been identified as an alternative form of removing transformed cells when p53-driven apoptosis is disturbed (7-11). In addition, activating necroptosis may serve as a novel therapeutic strategy against neoplastic states for which conventional therapy remains ineffective (11).

The primary difference between apoptosis and necroptosis are the molecules which make up the signalling cascades; caspase for apoptosis and RIP1/RIP3 for necroptosis $(12,13)$. During necroptosis RIP1 and RIP3 form a complex, which triggers the highly regulated process of cell death. The RIP1/RIP3 cytoplasmic necroptotic protein complex is called a necrosome and constitutes a key molecular platform of necroptosis $(7,10,14,15)$. A number of factors may trigger nepoptosis, including tumour necrosis factor (TNF), Fas ligand and TNF-related apoptosis inducing ligand (8). The overproduction of reactive oxygen species (ROS) damages different macromolecules, including lipids, proteins and DNA and thereby may also contribute to the execution of necroptosis (8). 
The present study aimed to determine the association between the two different programmed cell death signalling pathways within a rat model of hepatocarcinogenesis, induced by partial hepatectomy (PH) and diethilnitrosamine (DEN) treatment. The present study investigated the hypothesis that necroptosis may have the potential to destroy neoplastic oval cells following the suppression of apoptosis.

\section{Materials and methods}

Experimental design. A total of 20 female Wistar rats (weight, 200-220 g) were used in the present study. The rats were obtained from the Centre of Experimental Medicine, The Medical University of Bialystok (Bialystok, Poland). The rats were housed in pairs in standard polysulfone cages $(59 \times 38 \times 20 \mathrm{~cm})$ containing wood-chip bedding material in a temperature $\left(22 \pm 1^{\circ} \mathrm{C}\right)$ and humidity-controlled $(50 \pm 10 \%)$ room with a 12 -h light/dark cycle. The animals had ad libitum access to standard rat pellet food and tap water. All procedures were approved by the Ethics Committee for Animal Experimentation at the University of Life Sciences (Lublin, Poland; approval number 81/2015).

Following a 1-week period of acclimatisation the 10-week-old rats were divided into two groups for OC induction: i) Non-neoplastic PH, PH was performed and PBS was administered in the drinking water $(n=10)$; and ii) neoplastic $\mathrm{PH} / \mathrm{DEN}$, a two-step rat model of hepatocarcinogenesis was performed following the Solt-Farber protocol $(n=10)(16)$. A PH (two-thirds) was performed to the rats in each group according to the Higgins and Anderson method via excision of left lateral $(\sim 38 \%)$ and right $(\sim 30 \%$ lobes as previously described (17). All surgical procedures were performed under ketamine and xylazine anaesthesia $(90 \mathrm{mg} / \mathrm{kg}$ and $10 \mathrm{mg} / \mathrm{kg}$, respectively) between 9.00 a.m. and 12.00 p.m. to minimise the diurnal effect of liver regeneration. At 7 days following PH, DEN (50 mg/l; Sigma Aldrich; Merck KGaA, Darmstadt, Germany) was added to the drinking water of the neoplastic group of rats and supplied ad libitum for a period of 10 weeks. The non-neoplastic group were administered PBS. Following this 10 -week period, an exploratory laparotomy was performed in the PH/DEN rats and the development of tumours on the liver surface was confirmed.

In vivo and in vitro experimental design. After 10 weeks OCs were isolated from each group as described previously (4). OC cells were isolated during the exploratory laparotomy in the $\mathrm{PH} / \mathrm{DEN}$ group and during a regular laparotomy in the $\mathrm{PH}$ group. Prior to the laparotomy, rats were anesthetised with intramuscular administration of ketamine (90 mg/kg) and xylazine $(10 \mathrm{mg} / \mathrm{kg}$ ). The liver was perfused in situ through the portal vein with a Krebs-Ringer buffer (Sigma Aldrich; Merck KGaA) made up of three parts as follows: i) Containing EGTA, ii) without $\mathrm{Ca}^{2+}$ and chelating agent and iii) with type IV collagenase. Following perfusion, the liver was transferred to Ham's F-12/Dulbecco's modified Eagle's medium (DMEM; 1:1 v/v; Sigma Aldrich; Merck $\mathrm{KGaA}$ ), minced, filtered through a double gauze and digested for $1 \mathrm{~h}$ at $37^{\circ} \mathrm{C}$ in PBS containing $0.1 \%$ collagenase, $0.25 \%$ trypsin, $0.004 \%$ DNase I and $0.1 \%$ pronase E (all Sigma Aldrich; Merck KGaA), which selectively digested mature hepatocytes into undetectable debris. The mixture was subsequently decanted through a $70 \mu$ m-nylon mesh followed by a $40 \mu$ m-nylon mesh and then loaded on a discontinuous gradient of Percoll and centrifuged at $420 \mathrm{x} \mathrm{g}$ for $20 \mathrm{~min}$ at $4^{\circ} \mathrm{C}$. Density gradient centrifugation is an effective method of separating OCs from the remaining liver cell fractions (12). In comparison with the other methods, including flow cytometry and immunomagnetic sorting, density gradient centrifugation in Percoll, followed by specific enzymatic digestion leads to the isolation of pure OCs with a high viability (18-19).

The collected cell suspension was washed with antibiotic supplemented $(100 \mathrm{U} / \mathrm{ml}$ penicillin, $0.1 \mathrm{mg} / \mathrm{ml}$ streptomycin, $10 \mathrm{mg} / \mathrm{ml}$ gentamycin) Ham's F-12/DMEM medium containing $10 \%$ fetal calf serum (Sigma Aldrich; Merck KGaA) and plated at 250,000 cells/well in 1,000 $\mu \mathrm{l} \mathrm{Ham}$ 's F-12/DMEM $(1: 1 \mathrm{v} / \mathrm{v})$ medium in a $24-w e l l$ plate at $37^{\circ} \mathrm{C}$ with $5 \% \mathrm{CO}_{2}$. The viability of the cells was estimated using the Trypan-blue exclusion method and was between 75-85\%. A total of $180 \mu \mathrm{l}$ Trypan blue (Sigma Aldrich; Merck KGaA) was mixed with $20 \mu \mathrm{l}$ cell suspension and $50 \mu \mathrm{l}$ of the mixture was dropped on a Bürker counting chamber. The number of viable cells (with a clear cytoplasm) and dead cells (with a blue cytoplasm) was determined in 24 squares $\left(0.25 \mathrm{~mm}^{2}\right)$ of the Bürker chamber as previously described (20). Adhered OCs from the PH and $\mathrm{PH} / \mathrm{DEN}$ groups were cultured in HAMS-12/DMEM (v/v) medium at $37^{\circ} \mathrm{C}$ with $5 \% \mathrm{CO}_{2}$. The medium and cells were analysed at 24, 48 and $72 \mathrm{~h}$, and the first and second week of incubation.

Biochemical analysis. Serum levels of alanine aminotransferase (ALT; cat. no. A11A01627), aspartate aminotransferase (AST; cat. no. A11A01629), $\gamma$-glutamyl transferase (GGT; cat. no. A11A01630) and alkaline phosphatase (AP; cat. no. A11A01626) were quantified using a kinetic methods with an ABX Pentra 400 (HORIBA Ltd., Kyoto, Japan) using commercially available tests from HORIBA Ltd. All procedures were performed according manufacture's protocol.

Histopathological examination of the liver tissue. Liver tissues were fixed for $24 \mathrm{~h}$ at room temperature in $10 \%$ phosphate-buffered formalin, embedded in paraffin and sectioned at 3-5 $\mu \mathrm{m}$ using a rotary microtome (Leica SR-200; Leica Microsystems, Ltd., Milton Keynes, UK) prior to histological examination. The sections were stained at room temperature with haematoxylin $(5 \mathrm{~min})$ and eosin $(5 \mathrm{~min})$ for histological observation. The histological analyses were performed via light microscopy (Eclipse E-600; Nikon Corporation, Tokyo, Japan) at magnification, x200. The hepatic injures were assessed according to the World Health Organisation Histological Classification of Tumours (21).

Morphological characterisation of isolated OCs. The OCs were cultured at $36^{\circ} \mathrm{C}$ for 2 weeks in Ham's F-12/DMEM mixture $(1: 1 \mathrm{v} / \mathrm{v})$. On each day of culture the OCs were subjected to microscopic analysis of the morphology under a phase-contrast microscope (Olympus CK40; Olympus Corporation, Tokyo, Japan). The appearance of the cells, colony formation, spread of cell culture and the construction or lack of a monolayer was analysed. 
Western blot analysis. At various time points $(24,48,72 \mathrm{~h}$ and 1st and 2nd week) the OCs were harvested in a lysis buffer composed of $0.2 \%$ Nonidet-P40, $150 \mathrm{mmol} / 1 \mathrm{NaCl}$, $20 \mathrm{mmol} / \mathrm{l}$ Tris, $2 \mathrm{mmol}$ EDTA, $0.1 \%$ glycerol, $10 \mathrm{mmol} / \mathrm{l}$ dithiothreitol and a cOmplete ${ }^{\mathrm{TM}}$ protease inhibitor cocktail (Roche; Sigma-Aldrich; Merck KGaA). Concentration of obtained protein was analysed by Lowry method (22). Equal amounts (30 $\mu \mathrm{g} / \mathrm{lane})$ of protein were separated by $12 \%$ SDS-PAGE, transferred to polyvinylidene difluoride membranes (Bio-Rad Laboratories, Inc., Hercules, CA, USA) and blocked for $1 \mathrm{~h}$ at $20^{\circ} \mathrm{C}$ with PBS containing 5\% low-fat milk. Following washing with Tris-buffered saline and $0.1 \%$ Tween-20 (Sigma Aldrich; Merck KGaA), the membranes were incubated overnight at $4^{\circ} \mathrm{C}$ with primary antibodies directed against cytokeratine-19 (CK19; 1:200; cat. no. M0888), albumin (Alb; 1:1,000; cat. no. F0117; both Dako; Agilent Technologies, Inc., Santa Clara, CA, USA), $\alpha$-fetoprotein (Afp; cat. no. ab46799), RIPK1 (cat. no. ab106393) and RIPK3 (cat. no. ab56164) (all 1:200; Abcam, Cambridge, UK). The washed membranes were subsequently incubated for $3 \mathrm{~h}$ at $4^{\circ} \mathrm{C}$ with alkaline phosphatase-labelled goat anti-mouse (cat. no. P0447) or anti-rabbit (cat. no. P0448) (both 1:15,000; Dako; Agilent Technologies, Inc.) secondary antibodies. The protein bands were visualised using colorimetric detection (GelDog XR system; Bio-Rad Laboratories, Inc.) and analysed using Quantity One 1-D analysis software version 4.6.3 (Bio-Rad Laboratories, Inc.) (4).

Apoptosis detection using flow cytometry (FCM). Apoptosis detection was performed using an Annexin V/FITC assay kit (Bio-Rad Laboratories, Inc.) according to the manufacture's protocol. The OCs were washed in PBS and centrifuged at $420 \mathrm{x}$ g for $10 \mathrm{~min}$ at $4^{\circ} \mathrm{C}$ and the supernatant was discarded. The cell pellet was suspended in the binding buffer and adjusted to a concentration of $5 \times 10^{5}$ cells $/ \mathrm{ml}$. A total of $5 \mu \mathrm{l}$ Annexin V-fluorescein isothiocyanate (FITC) solution was added and the cells were incubated for $15 \mathrm{~min}$ at room temperature in the dark. A total of $10 \mu \mathrm{l}$ propidium iodide (PI) was subsequently added and the probes were incubated for $15 \mathrm{~min}$ in the dark at room temperature. The suspension was subsequently centrifuged at $300 \mathrm{x}$ g for $5 \mathrm{~min}$ at room temperature, re-suspended in $200 \mu \mathrm{l}$ binding buffer and analysed using System XL-II software with a Coulter Epics XL flow cytometer (Beckman Coulter, Inc., Brea, CA, USA) (23).

Cell proliferation assay. To detect the proliferation rate of $\mathrm{PH}$ and PH/DEN OCs, an ELISA- Bromodeoxyuridine (BrdU) kit (Abcam; cat. no. ab126556) was used according to the manufacturer's protocol. This test measures the BrdU incorporated into newly synthesised cellular DNA. The cells were seeded in a 96-well plate at a density of $2 \times 10^{5}$ cells/well in $100 \mu \mathrm{l} \mathrm{Ham}$ 's F-12/DMEM (1:1 v/v) culture medium. A total of $20 \mu 1$ diluted 1:500 $\mathrm{BrdU}$ was added to the OCs in the plates and incubated at $37^{\circ} \mathrm{C}$ for $4 \mathrm{~h}$ (BrdU incorporation). Following removal of the culture medium the cells were fixed for $30 \mathrm{~min}$ at room temperature with FixDenat (provided with the test kit) followed by incubation with peroxide-conjugated monoclonal antibodies to the thymidine-analogue 5-bromo-2'deoxyuridine Fab fragments, which bind with the incorporated DNA. Following the
Table I. Body weight and serum levels of AST, ALT, AP and GGT in a PH/DEN rat model of hepatocarcinogensis.

\begin{tabular}{lcc}
\hline Characteristic & PH rats & PH/DEN rats \\
\hline Initial weight $(\mathrm{g})$ & $215.00 \pm 5.37$ & $209.00 \pm 7.20$ \\
Final weight $(\mathrm{g})$ & $300.00 \pm 6.63$ & $266.00 \pm 10.80^{\mathrm{a}}$ \\
AST (U/l) & $107.00 \pm 6.68$ & $204.25 \pm 23.04^{\mathrm{a}}$ \\
ALT (U/l) & $49.25 \pm 3.09$ & $71.65 \pm 2.75^{\mathrm{a}}$ \\
AP (U/l) & $73.25 \pm 4.34$ & $137.75 \pm 9.10^{\mathrm{a}}$ \\
GGT (U/l) & $5.47 \pm 0.25$ & $59.25 \pm 9.57^{\mathrm{a}}$ \\
\hline
\end{tabular}

Data are presented as the mean \pm standard deviation. ${ }^{\mathrm{a}} \mathrm{P}<0.05$ vs. $\mathrm{PH}$ rats. AST, aspartate aminotransferase; ALT, alanine aminotransferase; AP, alkaline phosphatase; GGT, $\gamma$-glutamyl transferase; PH, partial hepatectomy; DEN, diethylnitrosamine.

addition of substrate solution, the immune complexes were detected at $450 \mathrm{~nm}$ using an ELx800 ${ }^{\mathrm{TM}}$ ELISA reader (BioTek Instruments, Inc., Winooski, VT, USA).

Superoxide anion assay. Superoxide anion production was measured as previously described (23). OCs were incubated with $0.1 \%$ nitroblue tetrazolium (Sigma-Aldrich; Merck $\mathrm{KGaA}$ ) solution at room temperature for $10 \mathrm{~min}$ and the absorbance was read at $545 \mathrm{~nm}$. Nanomoles of superoxide produced over the incubation period were calculated using the extinction coefficient of $21.1 \mathrm{nmol}(24)$.

Statistical analysis. All experiments were repeated a minimum of three times with different batches of cell samples. Data are presented as the mean \pm standard deviation. Data were analysed using one-way analysis of variance (ANOVA) or Student's t-test as appropriate. When ANOVA indicated significant differences within groups, comparisons were made using Tukey's post hoc test. $\mathrm{P}<0.05$ was considered to indicate a statistically significant difference. Statistical analyses were performed using STATISTICA version 13.1 software (StatSoft Ltd., Bedford, UK).

\section{Results}

Body weight and blood biochemical analyses. Rats in the PH/DEN group had a slower growth rate compared with the $\mathrm{PH}$ group. At the time of sacrifice the average body weight was significantly ( 20\%) lower in the PH/DEN group compared with the PH group (Table I). Blood analyses indicated that AST, ALT, AP and GGT levels were significantly higher in the PH/DEN group compared with the $\mathrm{PH}$ group (Table I).

Histological examination. The livers of the PH (Fig. 1A) and PH/DEN (Fig. 1B) rats were examined. Normal liver histology was observed in the $\mathrm{PH}$ group (Fig. 1C). The liver histology of animals in the PH/DEN group was characterised by chronic damage and areas of cellular atypia (black arrow; Fig. 1D). The signs included lymphocytic infiltration, cells with enlarged nuclei and atypical hepatocytes. 
A
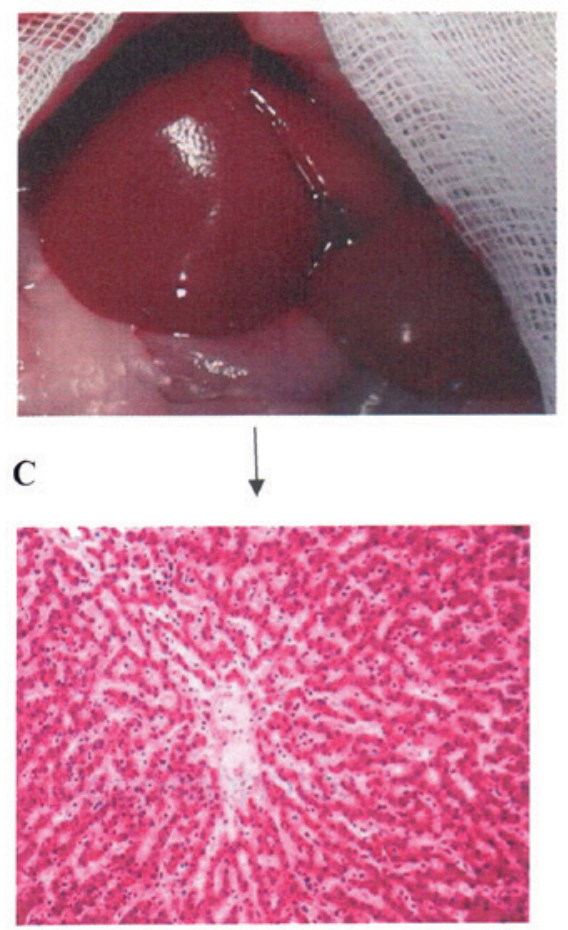

B PH/DEN rats (advanced HCC)

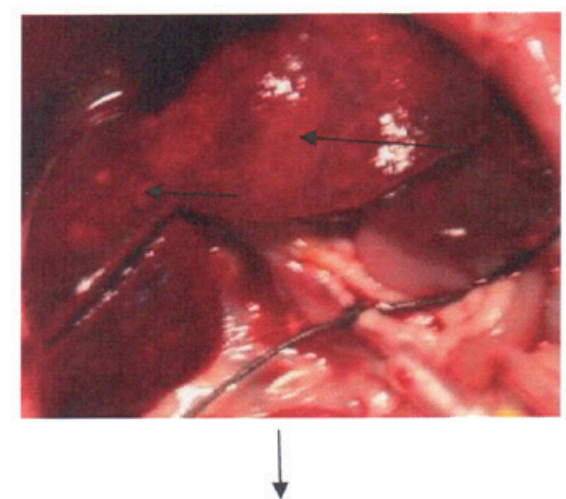

D

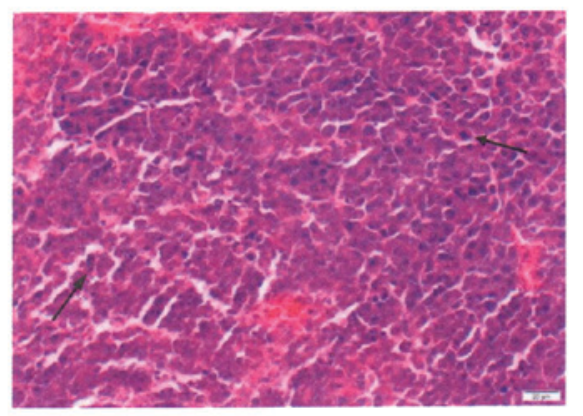

Figure 1. Representative macroscopic and microscopic features of the liver. (A) In PH rats treated with PBS, the liver appeared normal macroscopically, with visible lobule, (B) whereas the PH/DEN rats exhibited visible HCC (black arrows). (C) The PH rats exhibited normal hepatic parenchyma (D), whereas the $\mathrm{PH} / \mathrm{DEN}$ rats exhibited a number of white macronodules (black arrows). The mean number of hepatocellular nodules in this group was $26 \pm 4$ and their relative size was 1-3 mm. Haematoxylin and eosin staining demonstrated the nodular appearance of HCC with frequent atypical (bizarre) cells and mitotic figures (black arrows). HCC, hepatocellular carcinoma; PH, partial hepatectomy; DEN, diethylnitrosamine.

Phenotype of primary $P H$ and PH/DEN OCs. Western blot analysis was performed to detect the stem cell markers Afp, CK19 and Alb to determine whether rat OCs were activated in each group (Fig. 2A). Each group was positive for Afp and CK19, the classical OC markers immediately following isolation. The isolated OCs also co-expressed Alb at a high level. One way of defining a cell population as a progenitor $\mathrm{OC}$ is to clarify its ability to multiply and differentiate into hepatocytes and cholangiocytes. The freshly isolated cells expressed hepatocytic (Alb) and cholangiocytic markers (CK19), indicating that they were bipotential hepatic stem cells. Afp and CK19 were not detected in PH OCs following 2 weeks of incubation (whereas Alb was detected at all time points of the experiment), which indicates that PH OCs successively gave rise to novel hepatocytes. By contrast, the expression of Alb by $\mathrm{PH} / \mathrm{DEN}$ OCs gradually disappeared throughout incubation.

Freshly isolated OCs were round in shape and had a high nuclear to cytoplasmic ratio. PH OCs attached to the culture dish within $24 \mathrm{~h}$ and grew to confluence within $72 \mathrm{~h}$ as spindle-shaped cells (Fig. 2B). From the first week of incubation, the $\mathrm{PH}$ cells composed a flat monolayer and began to differentiate into cells of mature morphology, which was clearly visible in the second week of incubation (Fig. 2B). This maturation of cells was additionally confirmed by a strong Alb expression (Fig. 2A).

The PH/DEN group OCs expanded in the culture without creating a regular monolayer. It was observed that some of the cells were round mononuclear cells with an oval-like appearance, however some were longitudinal. Following 1 week of culture, the PH/DEN OCs aggregated and formed colonies. At 2 weeks incubation there was intensive multiplying of the OCs.

RIP1 and RIP3 protein expression alters under non-neoplastic and neoplastic conditions. OCs isolated from $\mathrm{PH}$ and PH/DEN livers expressed RIP1 and RIP3 protein throughout culture (Fig. 3). The expression of RIP1 and RIP3 proteins by OCs remained constant in the $\mathrm{PH}$ group, however, a notable increase in RIP1 and RIP3 protein expression was observed in the PH/DEN group following $72 \mathrm{~h}$ incubation (Table II). In addition, the bands density of RIP1 and RIP3 obtained in the 1st and 2nd week of PH/DEN OCs incubation, were significantly higher $(\mathrm{P}<0.05)$ compared with the $\mathrm{PH}$ group at the same time points (Table II). At the 2nd week the PH/DEN OCs exhibited the strongest staining of RIP1 and RIP3 at 3.488,89 and $3.547,67 \mathrm{INT} / \mathrm{mm}^{2}$, respectively (Table II). It appears that, conversely to non-neoplastic OCs, the time of incubation intensifies RIP1- and RIP3-dependent necroptotic death in neoplastic cells.

FITC-Annexin V/PI bivariate FCM. During the initial $48 \mathrm{~h}$ of $\mathrm{OC}$ incubation in the $\mathrm{PH}$ group, the mean number of apoptotic cells was $10.56 \pm 0.5 \%$ (Fig. 4). At $72 \mathrm{~h}$ the percentage of apoptotic cells significantly increased to $33.58 \pm 0.5 \%$, which was markedly decreased at 2 weeks $(30.08 \pm 0.83 \%)$. Compared with the PH OCs, the cells isolated from the $\mathrm{PH} / \mathrm{DEC}$ group exhibited significantly less apoptosis between $72 \mathrm{~h}$ and 2 weeks. There were particularly few apoptotic cells $(2.82 \pm 1.1 \%)$ in the PH/DEN group at $72 \mathrm{~h}$. The level of apoptosis in the PH/DEN group gradually 


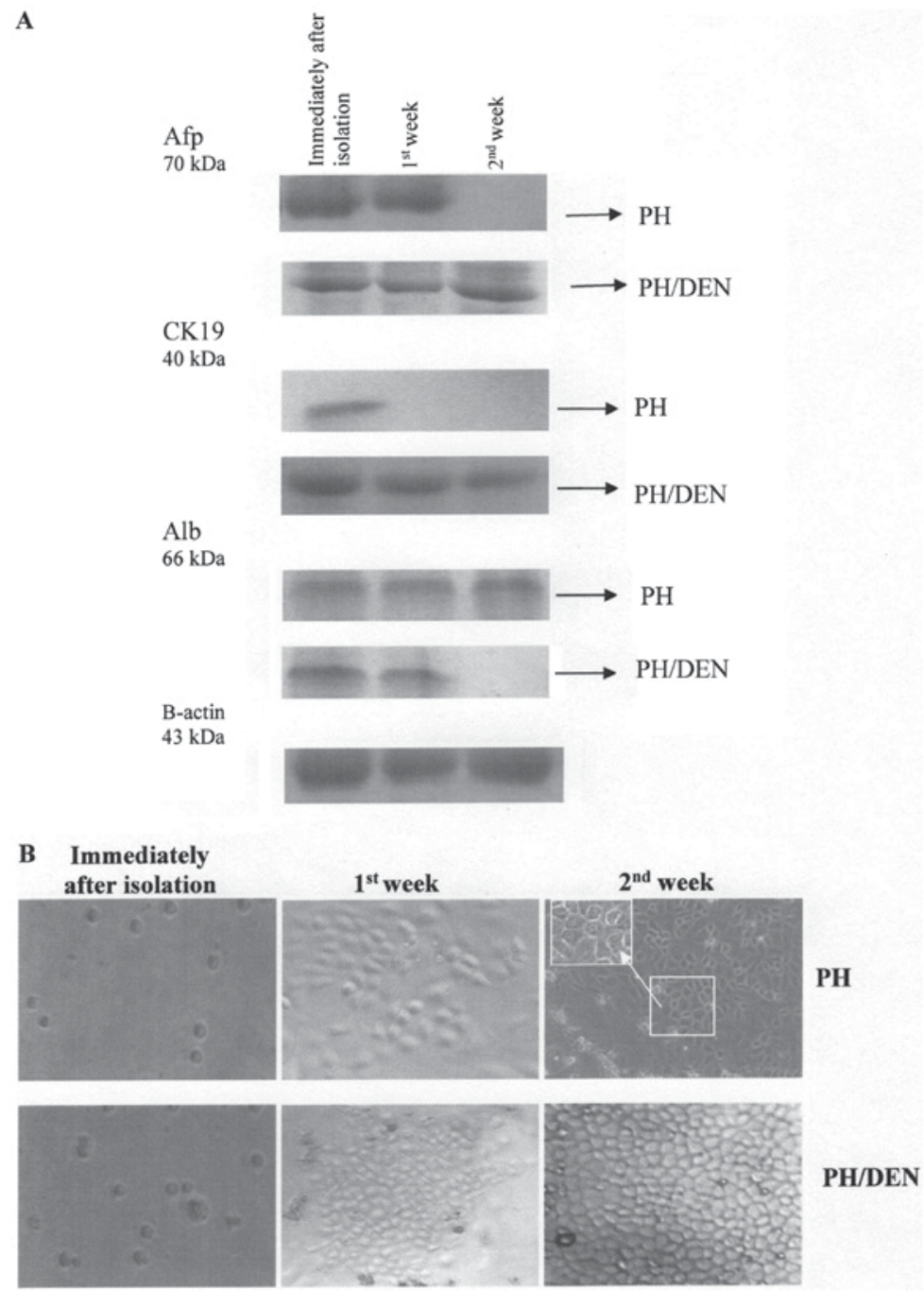

Figure 2. Protein expression of Afp, CK19 and Alb in PH and PH/DEN OCs. (A) Western blot analysis was performed to determine the protein expression of Afp, CK19 and Alb in PH and PH/DEN OCs. (B) Morphological phase-contrast characteristics of the isolated and cultured OCs. Immediately following isolation the OCs were small, with an oval-shaped nucleus and scant cytoplasm. Within the first week of incubation PH/DEN cells formed colonies and underwent clonal expansion with a high proliferative potential. Neither of the groups' cells exhibited a hepatic myofibroblast-like appearance. In the PH group following 2 weeks in culture, cells with abundant cytoplasm and round nuclei typical of mature hepatocytes were present. The polygonal shape of the PH OCs was visible in the high magnification of the bracketed area (x400). Magnification, x200. PH, partial hepatectomy; DEN, diethylnitrosamine; OC, oval cell; Alb, albumin; CK19, cytokeratine-19; Afp, $\alpha$-fetoprotein.

PH

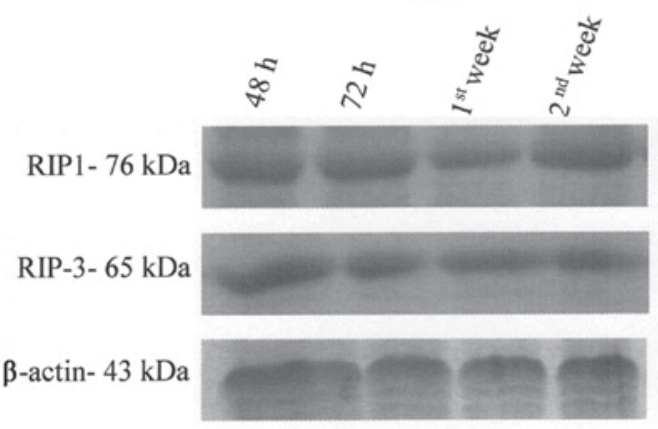

PH/DEN

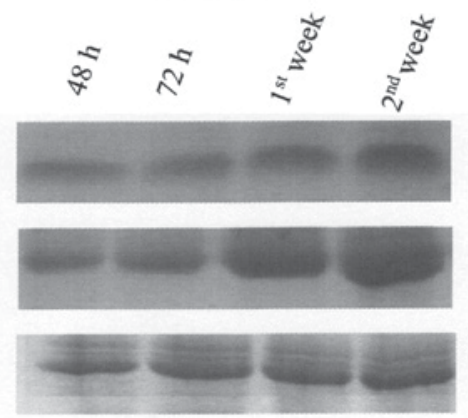

Figure 3. Protein expression of RIP1 and RIP3 in PH and PH/DEN OCs. Western blot analysis was performed to determine the protein expression of RIP1 and RIP3 in PH and PH/DEN OCs. The bands are representative of 3 separate experiments. $\beta$-actin ( $43 \mathrm{kDa}$ ) was used as a control of protein loading. PH, partial hepatectomy; DEN, diethylnitrosamine; RIP, receptor interacting protein; OC, oval cell.

increased and was significantly increased at 2 weeks compared with 1 week, however at no time point did it exceed $15.94 \pm 0.9 \%$ of all cultured cells. Concurrent staining with Annexin V and PI revealed differences between the percentage of apoptotic $\mathrm{PH}$ 
Table II. Protein expression of RIP1 and RIP3.

\begin{tabular}{|c|c|c|c|c|c|}
\hline \multirow[b]{2}{*}{ Protein } & \multirow[b]{2}{*}{ Time point } & \multicolumn{2}{|c|}{ PH } & \multicolumn{2}{|c|}{$\mathrm{PH} / \mathrm{DEN}$} \\
\hline & & \% Adj.Vol. & Density (INT/mm²) & $\%$ Adj.Vol. & Density (INT/mm²) \\
\hline \multirow[t]{4}{*}{ RIP1 } & $48 \mathrm{~h}$ & 12.47 & $2,924.40$ & 6.84 & $2,437.00^{\mathrm{a}}$ \\
\hline & $72 \mathrm{~h}$ & 10.92 & $2,879.56$ & 10.89 & $2,868.11$ \\
\hline & 1st week & 10.98 & $2,884.67$ & 16.20 & $3,246.00^{\mathrm{a}}$ \\
\hline & 2nd week & 12.49 & $2,938.56$ & 17.89 & $3,488.89^{\mathrm{a}}$ \\
\hline \multirow[t]{4}{*}{ RIP3 } & $48 \mathrm{~h}$ & 14.57 & $3,163.56$ & 12.43 & $2,914.89$ \\
\hline & $72 \mathrm{~h}$ & 13.34 & $3,015.11$ & 13.40 & $3,069.78$ \\
\hline & 1st week & 9.95 & $2,833.11$ & 16.28 & $3,360.89^{\mathrm{a}}$ \\
\hline & 2nd week & 9.20 & $2,812.56$ & 18.20 & $3,547.67^{\mathrm{a}}$ \\
\hline
\end{tabular}

The density of bands was expressed by the pixels in the volume divided by the area of the volume. ${ }^{\text {a }}<0.05$ vs. PH rats. \% Adj.Vol., the volume expressed by the percentage of all the volumes in the image; PH, partial hepatectomy; DEN, diethylnitrosamine; RIP, receptor interacting protein; INT, intensity per $\mathrm{mm}^{2}$.

and PH/DEN OCs. Whereas in PH-OCs apoptosis intensified concomitantly with the time of incubation, (bottom and upper right quadrants) live neoplastic OCs dominated independently of the time of cell culture (bottom left quadrant).

Proliferation activity of isolated $\mathrm{PH}$ and PH/DEN OCs. The proliferative activity of PH OCs gradually increased from $24 \mathrm{~h}$ $(0.47 \pm 0.03)$ to the first week of incubation $(1.1 \pm 0.3)$, however at the second week there was a slight reduction $(0.98 \pm 0.1$; Fig. 5). In contrast, PH/DEN OCs demonstrated increased proliferative activity at each time point, reaching the highest value at the second week $(1.99 \pm 0.09)$. The proliferative activity of $\mathrm{PH} / \mathrm{DEN}$ OCs was significantly increased compared with the $\mathrm{PH}$ OCs at the same time point between $72 \mathrm{~h}$ and the second week.

ROS generation by $P H$ and PH/DEN OCs. ROS production by $\mathrm{PH}$ OCs increased gradually from $0.70 \pm 0.03$ to $2.50 \pm 0.37 \mathrm{nM} / 25 \times 10^{4}$ cells from $24 \mathrm{~h}$ to the first week of incubation (Table III). PH/DEN OCs generated significantly increased amounts of ROS at each time point compared with the $\mathrm{PH}$ group, The highest ROS production occurred in the first week of cell incubation in each group and reached $2.50 \pm 0.37 \mathrm{nM} / 2.5 \times 10^{4}$ cells in the $\mathrm{PH}$ group and $3.70 \pm 0.27 \mathrm{nM} / 2.5 \times 10^{4}$ cells in the $\mathrm{PH} / \mathrm{DEN}$ group. Despite the slight decrease in ROS production $\left(3.2 \pm 0.37 \mathrm{nM} / 2.5 \times 10^{4}\right.$ cells) at the 2 nd week in the $\mathrm{PH} / \mathrm{DEN}$ group, this value was still significantly increased compared with the $\mathrm{PH}$ group.

\section{Discussion}

During the culture of PH OCs, RIP1 expression fluctuated between 10.92 and $12.49 \%$, while RIP3 expression steadily decreased from 14.57-9.20\%. At 48 h RIP1 and RIP3 expression was notably lower in the PH/DEN group, however it steadily increased over time and was significantly higher at 2 weeks compared with the PH group. In addition, it was connected with a high percentage of apoptotic cells, particularly after $48 \mathrm{~h}$ of PH OCs culture; it appears that apoptosis dominates in isolated PC OCs. Conversely it was observed that RIP1 and RIP3 expression increased concomitantly with apoptosis suppression in OCs obtained from the PH/DEN group. However, at all time points these cells exhibited a stronger RIP3 expression compared with RIP1. These slight but visible differences in RIP1 and RIP3 expression in PH/DEN OCs indicated that RIP1 may be dispensable for necroptosis induction and that RIP3 serves a pivotal role during necroptosis induction. According to Kearney et al (25) RIP1 knockdown accelerated necroptosis induced by different stimuli and acts as an inhibitor of the process rather than a stimulator. In addition, Upton et al (26) reported that necroptosis induced by murine cytomegaloviruses went preferentially via the RIP3-dependent pathway as opposed to the RIP1-dependent pathway. A number of previous studies have demonstrated that RIP1 and RIP3 are essential mediators of necroptosis, which interact via their RIP homotypic interaction motif domains (13,27-30). In this case execution of RIP1/RIP3 interaction involves an active disintegration of mitochondrial, lysomal and plasma membranes (13).

Previous studies have revealed that apoptotic defects are the most frequent cause of cancer cell immortality and drug resistance, which limits the efficacy of cancer chemotherapy $(10,14)$. In the present study, the percentage of apoptotic PH/DEN OCs was lower than the percentage of apoptotic PH OCs at every time point. There was a significant apoptosis enhancement in the PH/DEN OCs at 2 weeks compared with $72 \mathrm{~h}$ and strong RIP1 expression was observed. These results suggest that as well as its association with necroptosis, RIP1 may be associated with the regulation of apoptosis $(12,29)$. In response to death receptor activation, a mitochondrial apoptogenic factor, such as Smac protein, induces the auto-degradation of cellular inhibitor of apoptosis protein (cIAP) 1 and cIAP2, which accelerates the formation of the RIP1-containing caspase- 8 activating complex $(12,28)$. Prolonged incubation of PH/DEN OCs intensifies caspase-dependent cell 


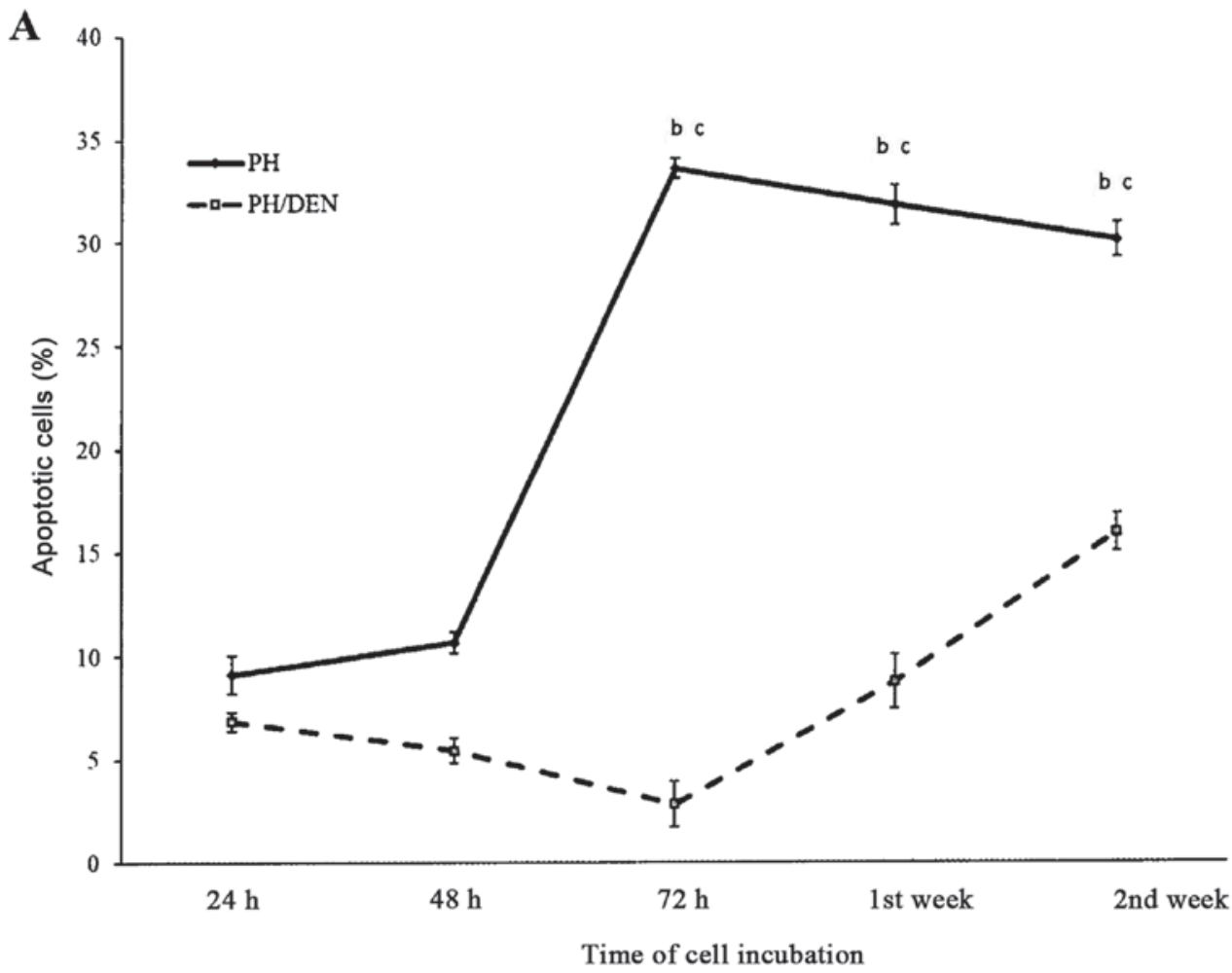

B

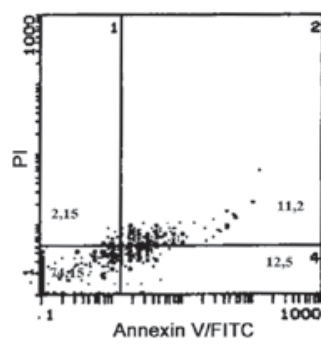

$24 \mathrm{~h}$

C

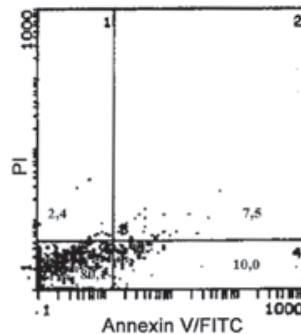

$24 \mathrm{~h}$

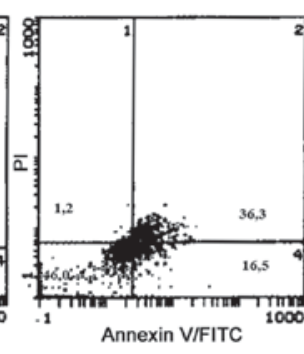

$72 \mathrm{~h}$

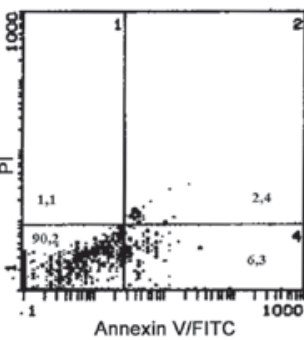

$72 \mathrm{~h}$

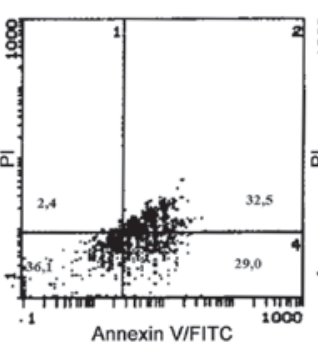

1 st week

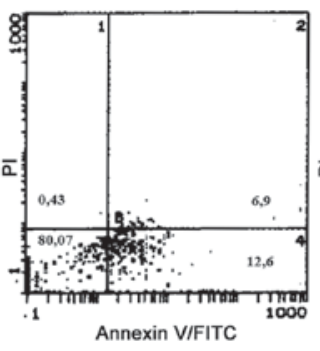

1 st week

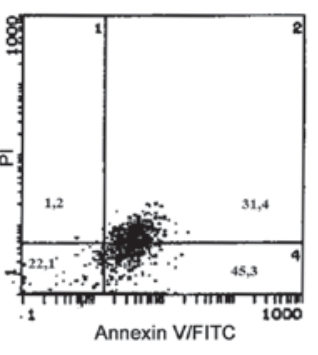

2nd week

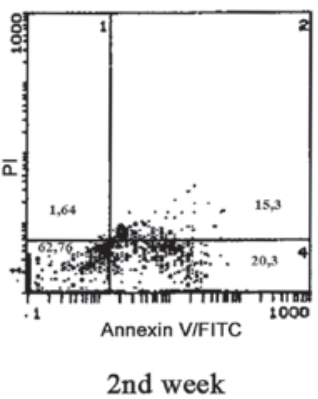

Figure 4. Flow cytometry analysis of apoptotic OCs. Flow cytometry was used to determine the percentage of apoptotic OCs in the PH group and PH/DEN group (A). Representative scatters of the flow cytometry analysis in the PH and PH/DEN groups. Representative graphs of the flow cytometry analysis in the (B) $\mathrm{PH}$ and (C) $\mathrm{PH} / \mathrm{DEN}$ groups. The data are presented as the means \pm standard deviation of 3 independent experiments. ${ }^{\mathrm{b}} \mathrm{P}<0.05 \mathrm{vs}$. $\mathrm{PH} / \mathrm{DEN}$ at the same time point; ${ }^{\mathrm{C}} \mathrm{P}<0.05 \mathrm{vs}$. $\mathrm{PH}$ at $48 \mathrm{~h}$. Representative images of 3 independent experiments are presented. $\mathrm{PH}$, partial hepatectomy; DEN, diethylnitrosamine; OC, oval cell; PI, propidium iodide.

death but not at the same level as that obtained in PH OCs. Schattenberg et al (9) previously reported that the failure of transformed neoplastic cells to undergo apoptosis severely disrupts tissue homeostasis and allows proliferation of the resistant clone, which is a phenomenon frequently observed in HCC. Similarly, the PH/DEN OCs cultured in the present study exhibited significantly increased proliferation activity compared with the PH OCs, particularly in the final week of incubation. Declercq et al (28) previously reported that when apoptotic cell death is reduced or blocked by caspase inhibitors, cells may use necroptosis as an alternative cell death pathway. The results of the present study support this suggestion. A number of previous studies have demonstrated that limited cancer necroptosis may contribute to tumour 
Table III. Superoxide generation by OCs isolated from $\mathrm{PH}$ and DEN rats $\left(\mathrm{nM} / 25 \times 10^{4}\right)$.

\begin{tabular}{|c|c|c|c|c|c|}
\hline Group & $24 \mathrm{~h}$ & $48 \mathrm{~h}$ & $72 \mathrm{~h}$ & 1st week & 2nd week \\
\hline $\mathrm{PH}$ & $0.70 \pm 0.03$ & $1.10 \pm 0.2$ & $2.20 \pm 0.43^{\mathrm{a}, \mathrm{b}}$ & $2.50 \pm 0.37^{\mathrm{a}, \mathrm{b}}$ & $2.00 \pm 0.31^{\mathrm{a}, \mathrm{b}}$ \\
\hline $\mathrm{PH} / \mathrm{DEN}$ & $1.67 \pm 0.36^{\mathrm{a}}$ & $1.89 \pm 0.5$ & $3.20 \pm 0.58^{\mathrm{a}, \mathrm{b}}$ & $3.70 \pm 0.27^{\mathrm{a}, \mathrm{b}}$ & $3.20 \pm 0.37^{\mathrm{a}, \mathrm{b}}$ \\
\hline
\end{tabular}

${ }^{\mathrm{a}} \mathrm{P}<0.05$ vs. $24 \mathrm{~h}$ PH group. ${ }^{\mathrm{b}} \mathrm{P}<0.05$ vs. 24 h $\mathrm{PH} / \mathrm{DEN}$. $\mathrm{PH}$, partial hepatectomy; DEN, diethylnitrosamine.

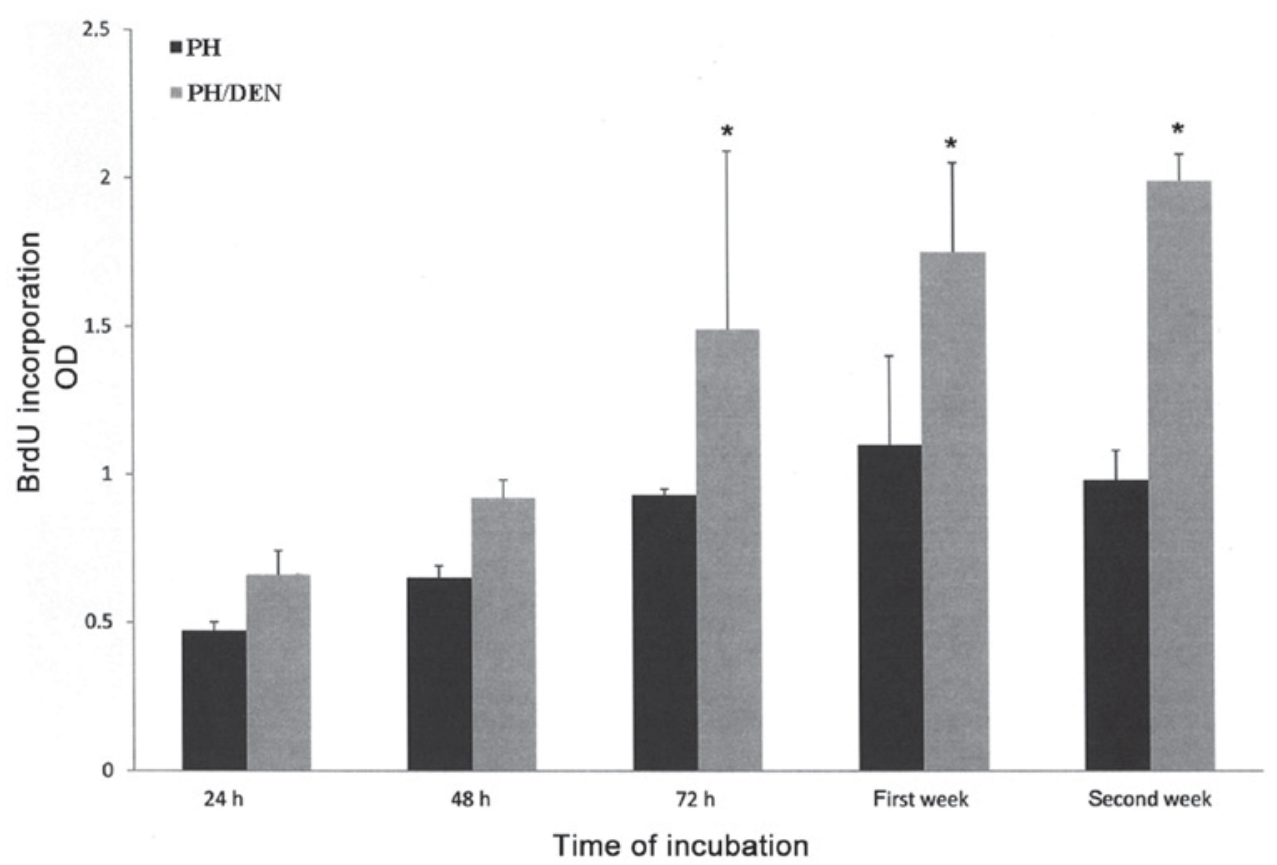

Figure 5. Proliferative activity of PH and PH/DEN OCs. BrdU incorporation into newly synthesized DNA of replicating cells was assessed using a monoclonal anti-BrdU antibody and a subsequent colorimetric detection. Data are presented as the mean \pm standard deviation. From $72 \mathrm{~h}$ of incubation, PH/DEN OCs exhibited significantly enhanced BrdU incorporation compared with PH OCs. " $\mathrm{P}<0.05$ vs. the PH group at the same time point. PH, partial hepatectomy; DEN, diethylnitrosamine; OC, oval cell; BrdU, bromodeoxyuridine; OD, optical density.

formation and resistance to cancer therapies $(7,14,15,30)$. In addition, it has been previously reported that the inhibition of caspase activity, one of the hallmarks of apoptosis, enhances necroptosis $(7,14)$. The results of the present study revealed that a low level of apoptosis $\mathrm{PH} / \mathrm{DEN}$ OCs was associated with higher RIP3 expression. The authors suggest that although this response enhances necroptotic cell death, it is not enough to break the highly proliferative activity of neoplastic OCs. The results indicated an increased level of superoxide released by $\mathrm{PH} / \mathrm{DEN}$ OCs, which may participate in the regulation of necroptotic response. The ROS may act as a stimuli of necroptosis (27). Christofferson and Yuan (27) demonstrated that ROS acts as an effector of necroptosis in a cell-type-dependent manner, which was reflected by the intensified proliferation of PH/DEN OCs under experimental conditions in the present study.

The results of the present study indicated that although $\mathrm{PH} / \mathrm{DEN}$ OCs demonstrated high proliferative activity with apoptosis suppression, their necroptosis potential was preserved. This was reflected by the pronounced expression of RIP3 and unchanged expression of RIP1. Optimal necroptosis may serve as an effective treatment for hepatocarcinogenesis and these findings clarify the importance of this alternative pathway of programmed cell death.

\section{Acknowledgements}

Not applicable.

\section{Funding}

The present study was supported by a grant from the National Science Centre in Poland (grant no. DEC-2014/15/B/ Nz5/01587).

\section{Availability of data and materials}

All data generated or analysed during this study are included in this published article.

\section{Authors' contributions}

MW isolated and cultured the OCs, performed western blot analysis, analysed cell proliferation and ROS generation and 
prepared the manuscript. RB performed statistical analysis and revised the manuscript prior to submission. UL determined apoptosis in OCs by flow cytometry. AŚ performed histopathological examination of the liver slides.

\section{Ethics approval and consent to participate}

The present study was approved by the Ethics Committee for Animal Experimentation at The University of Life Sciences (Lublin, Poland; approval number 81/2015).

\section{Consent for publication}

Not applicable.

\section{Competing interests}

The authors confirm that they have no competing interests.

\section{References}

1. Schlageter M, Terracciano LM, D'Angelo S and Sorrentino P: Histopatholgy of hepatocellular carcinoma. World J Gastroenterol 20: 15955-15964, 2014.

2. Zou C, Zhang H, Li Q, Xiao H, Yu L, Ke S, Zhou L, Liu W, Wang W, Huang H, et al: Heme-oxygenase-1: A molecular brake on hepatocellular carcinoma cell migration. Carcinogenesis 32 : 1840-1848, 2011

3. Lee KP, Lee JH, Kim TS, Park HD, Byun JS, Kim MC, Jeong WI, Calvisi DF, Kim JM and Lim DS: The Hippo-Salvador pathway restrains hepatic oval cell proliferation, liver size, and liver tumorigenesis. Proc Natl Acad Sci USA 107: 8248-8253, 2010.

4. Wójcik M, Bobowiec R and Martelli F: Effect of carotenoids on in vitro proliferation and differentiation of oval cells during neoplastic and non-neoplastic liver injures in rats. J Physiol Pharmacol 59 (Suppl 2): S203-S213, 2008.

5. Zheng T, Wang J, Jiang $\mathrm{H}$ and Liu L: Hippo signalling in oval cells and hepatocarcinogenesis. Cancer Lett 302: 91-99, 2011.

6. Jin J, Jin X, Qian C, Ruan Y and Jiang H: Signaling network of OSW-1-induced apoptosis and necroptosis in hepatocellular carcinoma. Mol Med Rep 7: 1646-1650, 2013.

7. Fulda S: The mechanism of necroptosis in normal and cancer cell. Cancer Biol Ther 14: 999-1004, 2013.

8. Jouan-Lanhouet S, Riquet F, Duprez L, Vanden Berhe T, Takahashi $\mathrm{N}$ and Vandenabeele P: Necroptosis, in vivo detection in experimental disease models. Semin Cell Devel Biol 35: 2-13, 2014.

9. Schattenberg JM, Schumann M and Galle PR: Cell death and hepatocarcinogenesis: Dysregulation of apoptosis signaling pathways. J Gastroenterol Hepatol 26 (Suppl 1): S213-S219, 2011

10. Hu X, Han W and Li L: Targeting the weak point of cancer by induction of necroptosis. Autophagy 3: 490-492, 2007.

11. Jiang L, Kon N, Li T, Wang SJ, Su T, Hibshoosh H, Baer R and $\mathrm{Gu}$ W: Ferroptosis as a p53-mediated activity during tumor suppression. Nature 520: 57-62, 2015.
12. He S, Wang L, Miao L, Wang T, Du F, Zhao L and Wang X: Receptor interacting protein kinase-3 determines cellular necrotic response to TNF-alpha. Cell 137: 1100-1111, 2009.

13. Vandenabeele P, Galluzi L, Vanden Berghe T and Kroemer G: Molecular mechanisms of necroptosis: An ordered cellular explosion. Nat Rev Mol Cell Biol 11: 700-714, 2010.

14. Fulda S: Therapeutic exploitation of necroptosis for cancer therapy. Semin Cell Dev Biol 35: 51-56, 2014.

15. Saeed WK and Jun DW: Necroptosis: An emerging type of cell death in liver diseases. World J Gastroenterol 20: 12526-12532, 2014.

16. Solt D and Farber E: New principle for the analysis of chemical carcinogenesis. Narure 263: 701-703, 1976.

17. Higgins $G$ and Anderson G: Experimental pathology of the liver restoration of the liver of the white rat following partial surgical removal. Arch Pathol (Chic) 12: 186-202, 1931.

18. Shupe TD, Piscaglia AC, Oh SH, Gasbarrini A and Petersen BE: Isolation and characterization of hepatic stem cells, or 'oval cells,' from rat livers. Method Mol Biol 482: 387-405, 2009.

19. He ZP, Tan WQ, Tang YF, Zhang HJ, and Feng MF: Activation, isolation, identification and in vitro proliferation of oval cells from adult rat livers. Cell Prolif 37: 177-187, 2004.

20. Strober W: Trypan blue exclusion test of cell viability. Curr Protoc Immunol 21: 3B:A.3B.1-A.3B.2, 2001.

21. Head KW, Cullen JM, Dubielzig RR, Else RW, Misdorp W, Patnaik AK, Tateyama S and Van Der Gaag I: Histological Classification of Tumors of the Alimentary System of Domestic Animals. Second Series. WHO, Armed Forces Institute of Pathology, Washington, DC, 2003.

22. Lowry OH, Rosebrough NJ, Farr AL and Randall RJ: Protein measurement with the Folin phenol reagent. J Biol Chem 193: 265-275, 1951.

23. Wójcik M, Bobowiec R, Lisiecka U and Kostro K: Proliferation, differentiation and apoptosis of choline deficient ethionine supplemented diet-rat oval cells under the influence of 2-methoxyestradiol. J Physiol Pharmacol 63: 669-676, 2012.

24. Wójcik M, Wessely-Szponder J and Kosior-Korzecka U: Proliferative and oxidative response of hepatocytes (Hep) and hepatic stellate cells (HSC) isolated from rats exposed to ketogenic diet. Pol J Vet Sci 17: 703-711, 2014.

25. Kearney CJ, Cullen SP, Clancy D and Martin SJ: RIPK1 can function as an inhibitor rather than an initiator of PIPK3-dependent necroptosis. FEBS J 281: 4921-4934, 2014.

26. Upton JW, Kaiser WJ and Mocarski ES: DAI/ZBP1/DLM-1 complexes with RIP3 to mediate virus-induced programmed necrosis that is targeted by murine cytomegalovirus VIRA. Cell Host Microbe 15: 290-297, 2012.

27. Christofferson DE and Yuan J: Necroptosis as an alternative form of programmed cell death. Curr Opin Cell Biol 22: 263-268, 2010.

28. Declercq W, Vanden Berghe T and Vandenabeele P: RIP kinase at the crossroads of cell death and survival. Cell 138: 229-232, 2009.

29. Newton K: RIPK1 and RIPK3: Critical regulators of inflammation and cell death. Trends Cell Biol 25: 347-353, 2015.

30. Zhou W and Yuan J: Necroptosis in health and diseases. Semin Cell Dev Biol 35: 14-23, 2014. 